\title{
Visualization Detection of Melamine in the Protein Feed
}

\author{
Shengbo Gao \\ Key Laboratory for Food Science and Engineering, Harbin University of Commerce \\ Harbin, China \\ 544546692@qq.com \\ Luoyun Zheng \\ 1 Key Laboratory for Food Science and Engineering, Harbin University of Commerce \\ Harbin,China \\ 506637547@qq.com \\ Tingting Yao \\ 1 Key Laboratory for Food Science and Engineering, Harbin University of Commerce \\ Harbin, China \\ 657407999@qq.com \\ Jiaying Xin * \\ Key Laboratory for Food Science and Engineering Harbin University of Commerce \\ Harbin, China \\ xinjiayingvip@163.com \\ * Corresponding Author
}

Keywords: Gold nanoparticles; Methanobactin; Protein feed; Melamine; Detection;

\begin{abstract}
Methane-oxidizing bacteria is the branches of methyl oxidation bacteria, It is a kind of gram-negative bacteria, which can directly use methane as carbon and energy sources. Methanobactin $(\mathrm{Mb})$ is a fluorescent peptide released by the Methane oxidizing bacteria. It consists of two serine, glycine, two cysteine and methionine. Methanobactin (Mb) can coordinate $\mathrm{Cu}(\mathrm{I})$ by two hydroxyimidazolates, with one $\mathrm{N}$ and one $\mathrm{S}$ atom. Methanobactin (Mb) can also bind to $\mathrm{Au}(\mathrm{III})$ and reduce it to $\mathrm{Au}(0)$. In the presence of hydroquinone as a electron donator, $\mathrm{Mb}$ can catalyze $\mathrm{Au}(\mathrm{III})$ reduce to $\mathrm{Au}(0)$ and yield gold nanoparticles continuously. Surface plasmon resonance of gold nanoparticles makes its aqueous solution has a typical absorption peak between 500 and 600nm, and a unique color of that can be observed by naked eyes. It can be identified by the color change and used in the detection of certain substances. In this paper, visual detection of melamine in protein feed based on methanobactin-( $\mathrm{Mb})$ induced gold nanoparticles formation was studied. Visual detection is convenient and quick. Different concentrations of melamine in protein feed have been detected. The interference of several kinds of ingredients in protein feed have been investigated. The detection limit and the recovery rate have been calculated, either. The detection limit of melamine is much lower than 1 ppm.
\end{abstract}

\section{Introduction}

Melamine (1,3,5-triazine, 2,4,6-triamine,) is a white crystalline powder type[1]. Its chemical formula is $\mathrm{C}_{3} \mathrm{~N}_{3}\left(\mathrm{NH}_{2}\right)_{3}$ and density is $1570 \mathrm{~kg} / \mathrm{m}^{3}$. Melamine can be dissolved in water, formic acid, 
acetic acid, methanol, pyridine, glycerine, hot ethylene glycol, and can not be dissolved carbon tetrachloride, acetone, benzene, and ethers. Melamine will slowly break down at $345{ }^{\circ} \mathrm{C}$, Its melting point is $250{ }^{\circ} \mathrm{C}(523 \mathrm{~K})$. Melamine is a non-combustible material. It is very stable at room temperature [2]. Melamine is weakly basic aqueous solution ( $\mathrm{PH}=8)$ and can form the melamine salt with $\mathrm{H}_{2} \mathrm{SO}_{4}$, $\mathrm{CH}_{3} \mathrm{COOH}, \mathrm{HNO}_{3}, \mathrm{H}_{2} \mathrm{C}_{2} \mathrm{O}_{4}, \mathrm{HCl}$ and other acids [3].

Melamine is forbidden to be used as an additive in food or related ingredients. Because of its high nitrogen content $(66 \%)$ and low cost, melamine was illegally adulterated in food products in order to increase apparent protein content. Standard tests such as the Kjeldahl and Dumas tests estimate protein levels of food products by measuring the nitrogen content. Thus, melamine was adulterated in protein-rich diets by unethical manufacturers. However, melamine could not be metabolized in human body, and could form insoluble complexes with cyanuric acid, depending on urine $\mathrm{pH}$, which could lead to crystallization and subsequent tissue injury. In this way, the excessive intake of melamine will result in the formation of insoluble

melamine cyanurate crystal in kidney and finally cause renal failure [4].Therefore, it is important to develop a reliable and highly sensitive sensor that can provide on-site and real-time detection of melamine in milk products. [5]

With recent developments in nanotechnology, new methods of designing colorimetric assays are emerging. The well-dispersed gold nanoparticles (GNPs) solution is red, whereas aggregated GNPs appear as a blue (or purple) colour. The GNPs-based colorimetric method has been recently used for the detection of various substances including DNA, metal ions and proteins [6]

The solution of gold nanoparticles has a specific color (red wine or grape purple) [7]. Melamine can prevent methanobactin-mediated synthesis of gold nanoparticles. There is no color change in the presence of melamine. In this paper, this fast way for detection of melamine in protein feed simple has been developed.

\section{Materials and methods}

Chemicals and Materials. Melamine (Mb) was obtained from Sigma -Aldrich (St. Louis, MO,USA). Chloroauric acid $\left(\mathrm{HAuCl}_{4} 4 \mathrm{H}_{2} \mathrm{O}\right)$ was obtained from Sinopharm Chemical Reagent Co. Ltd. (Shanghai, China). Other chemicals were of analytical reagent grade and used without further purification. All stock solution were prepared daily with distilled water.

Methylosinus trichosporium 3011 was obtained from the Institute of Microbiology and Virology (Kiev. Ukraine) [8].

Methylosinus Trichosporium IMV3011 Culture. Methylosinus trichosporium IMV3011 was maintained on mineral salt agar plates in a desiccator jar under an initial atmosphere of methane and air $(1: 10, \mathrm{~V} / \mathrm{V})$ at $30^{\circ} \mathrm{C}$. Cultures were transferred every 4 weeks. To prepare an inoculum for batch cultivation studies, $5 \mathrm{ml}$ of mineral salt medium was added to a 5-day-old agar plates; the agar plates was washed briefly to resuspend the cells, and the liquid was transferred to a $250 \mathrm{ml}$ closed flask containing $50 \mathrm{ml}$ of mineral salt medium. Cultures were grown on methane and air $(1: 10, \mathrm{~V} / \mathrm{V})$ at $30^{\circ} \mathrm{C}$ with shaking $(150 \mathrm{rpm})$. The gas phase of the bottle was refreshed by a gas mixture of methane and air $(1: 1, \mathrm{~V} / \mathrm{V})$ every $24 \mathrm{~h}$. The following mineral salt was used for cultivation, $(\mathrm{g} / \mathrm{L}): \mathrm{NH}_{4} \mathrm{Cl}, 0.5$; $\mathrm{K}_{2} \mathrm{HPO}_{4}, 0.49 ; \mathrm{KH}_{2} \mathrm{PO}_{4} \bullet 7 \mathrm{H}_{2} \mathrm{O}, 0.40 ; \mathrm{MgSO}_{4} \bullet 7 \mathrm{H}_{2} \mathrm{O}, 0.3 ; \mathrm{CaCl}_{2} \cdot 2 \mathrm{H}_{2} \mathrm{O}, 0.02 ; \mathrm{KNO}_{3}, 1.6 ; \mathrm{NaCl}, 0.3$; $\mathrm{FeSO}_{4} \cdot 7 \mathrm{H}_{2} \mathrm{O}, \quad 0.004 ; \quad \mathrm{CuSO}_{4} \cdot 5 \mathrm{H}_{2} \mathrm{O}, \quad 0.004 ; \quad \mathrm{MnSO}_{4} \cdot \mathrm{H}_{2} \mathrm{O}, \quad 0004 ; \quad \mathrm{ZnSO}_{4} \cdot 7 \mathrm{H}_{2} \mathrm{O}, \quad 0.00034 ;$ $\mathrm{Na}_{2} \mathrm{MoO}_{4} \cdot 2 \mathrm{H}_{2} \mathrm{O}, 0.00024$; $\mathrm{pH}$ 7.0. Methanobactin (Mb) sample was obtained from the methaneoxidizing bacteria fermenter broth,. A final solution would give a concentration of $10^{-3} \mathrm{M} \mathrm{Mb}$,

Isolation and Quantification of $\mathrm{Mb}$. $\mathrm{Mb}$ from the spent medium of Methylosinus richosporium 3011 was isolated as previously described for Methylococcus capsulatus Bath by Choi et al. The cells were removed by centrifugation at $10,000 \mathrm{~g}$ for $30 \mathrm{~min}$. The supernate was loaded onto a $2.5 \times$ $20 \mathrm{~cm}$ Diaion HP-20 column (Mitsubishi Chemical Holdings, Japan). The bound Mb was washed with two column volumes of $\mathrm{H}_{2} \mathrm{O}$ and eluted with $40 \%$ methanol: $60 \% \mathrm{H}_{2} \mathrm{O}$. The eluant was 
lyophilized for concentration and storage. The freeze-dried samples following chromatography on Diaion HP-20 columns were the source of Mb used in this study.

Protein Feed Sample Pretreatment. 3.2g protein fish feed was ground with a mortar and added $0.016 \mathrm{~g}$ of melamine. $8 \mathrm{~mL}$ of distilled water was added to dissolve the mixture $8 \mathrm{~mL}$ of $10 \%$ TCA solution was added and the samples were sonicated with a sonicator for $15 \mathrm{~min}$.. the resulting mixture was centrifuged at 10000rpm for 15 min to obtain the supernatant. [9]

Detection of Melamine in Protein Feed. Supermatant containing 1000ppm of melamine was diluted. The samples with the concentrations of $0.05,0.10,0.15,0.20,0.25,0.30,0.35,0.40,0.45$, $0.50,0.60,0.70 \mathrm{ppm}$ melamine were pre-treated respectively.

These supernatants were collected. 200ul supernatant protein feed containing different concentrations of melamine were detected as a sample and were added to 12 centrifuge tubes. Then all the tubes were added $\mathrm{Mb}$ solution $700 \mathrm{ul}\left(10^{-3} \mathrm{M}\right), 100 \mathrm{ul}$ of $\mathrm{HAuCl}_{4}$ solution $\left(10^{-2} \mathrm{M}\right)$. $0.1 \mathrm{M}$ sodium hydroxide has been used to adjust $\mathrm{pH}=5.1$, Full wavelength scan detection by UV - visible spectrophotometer between 200 800nm were carried out.

Calculation of Melamine Detection Limit. For this experiment, a zero concentration sample that is melamine-free was measured 20 times to calculate the standard deviation $\mathrm{S}$. Then sample containing a concentration of melamine was measured 20 times to calculate the standard deviation s', when $s^{\prime}=3 \mathrm{~s}$, the corresponding concentration of the solution is the limit of detection of melamine DL. [10]

\section{Results and Discussion}

Figure1 is the UV-visible absorbance values of gold nanoparticles obtained under protein feeds with different concentrations of melamine. As shown in Figure 1, the absorption of gold nanoparticles gradually decreases when the concentration of melamine increases. Almost no gold nanoparticles formed when the concentration of melamine is more than $0.7 \mathrm{ppm}$ This indicated that melamine can be completely blocked the $\mathrm{Mb}$-induced reducing of $\mathrm{Au}$ (III) and there is no gold nanoparticles formed when the presence of melamine. Also, the color of nanogold solution is red wine, there is the redshifted absorption in the presence of melamine, which result from the formation of gold nanoparticles with large particle size The color of the solution also tends to be more blue-black with the increase of the concentration of melamine. When the concentration of melamine is more than $0.7 \mathrm{ppm}$, a suddenly color-faded has been found and the formation of gold nanoparticles was completely blocked. There is no change in color of the solution, so the concentration of $0.7 \mathrm{ppm}$ is the basic concentration of melamine that can be visualized by the naked eye to achieve qualitative detection.

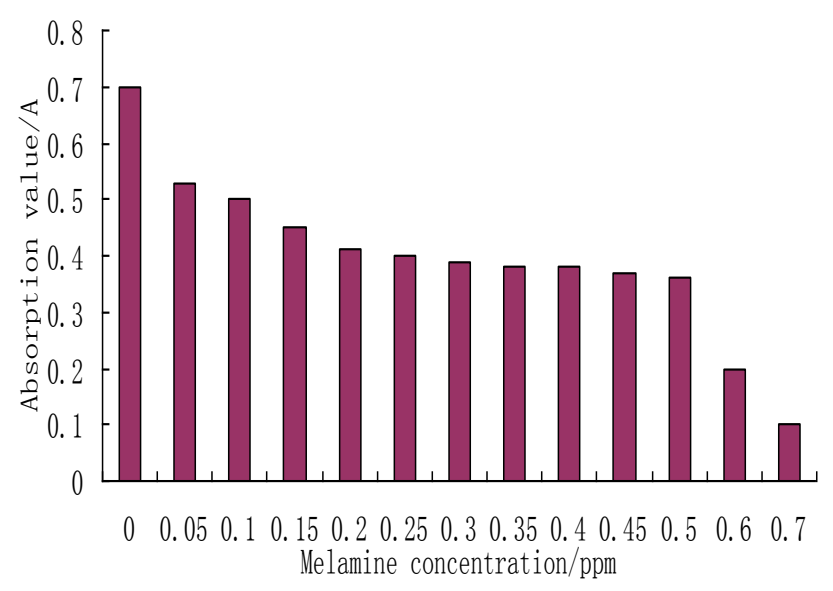

Figure 1. Absorption values of gold nanoparticles formed under the different concentrations of melamine

Figure 2 is the absorption values of gold nanoparticles under the corresponding concentration of melamine. The results showed that the higher the concentration of melamine, the lower the absorb 
value of the gold nanoparticles. The melamine concentrations observed at between $0.05 \sim 0.5 \mathrm{ppm}$ showed a good linear relationship between the absorption values of gold nanoparticles and the concentration of melamine. Therefore, the quantitative detection of the melamine can be achieved within the scope of this range

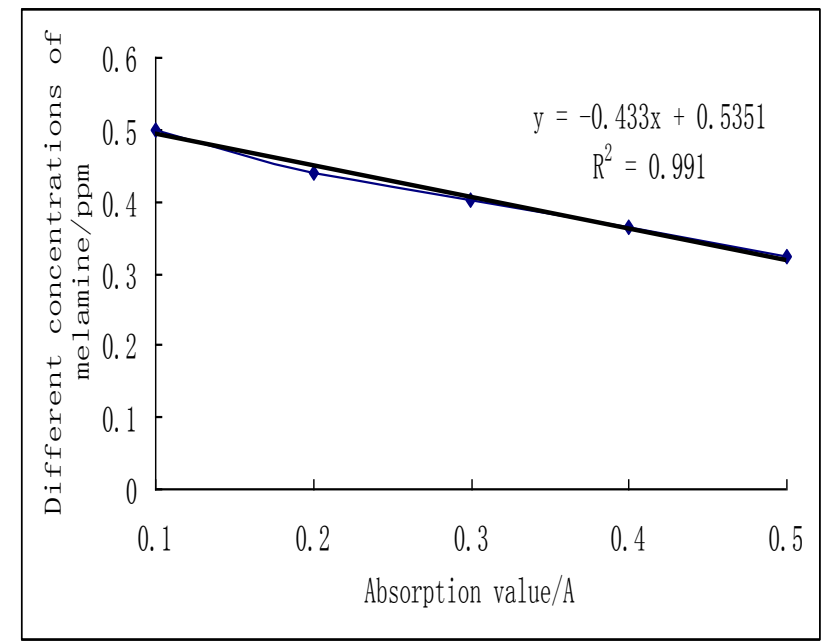

Figure 2. The linear relationship between melamine concentration and absorption values of gold nanoparticles $\left(\mathrm{R}^{2}=0.9685\right)$

Figure 3 is UV - visible absorbance of gold nanoparticles formed in the presence of $0.1,0.2,0.3,0.4$, $0.5 \mathrm{ppm}$ melamine, respectively A standard curve equation $\mathrm{y}=-0.0433 \mathrm{x}+0.5351$ can be calculated within this range of melamine concentration.

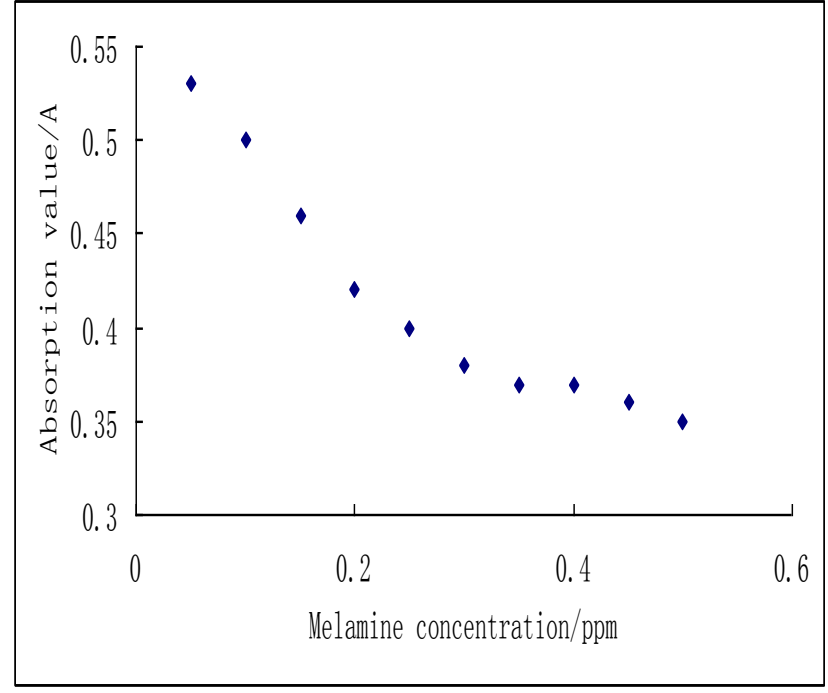

Figure 3. A standard curve of melamine concentration versus the absorbance of gold nanoparticulate

Figure 4 investigated the effect of potential interference factors in the protein feed on the measurement of melamine. 


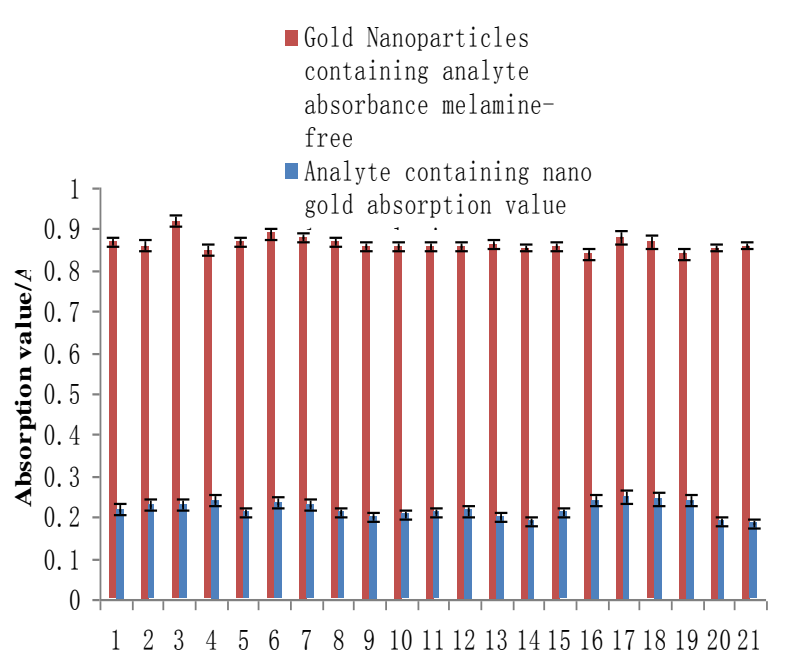

Figure 4. The absorption value of gold nanoparticles formed in the analyte containing melamine and melamine-free NOTE:

1.phenylalanine;2.arginine;3.Glu;4.alanine.acid;5.tyrosine;6.tryptophan;7.proline;8.methionine;9.lysi ne;10.uracil;11.sucrose;12.K+;13.glucose;14. $\mathrm{Na}_{3} \mathrm{PO}_{4} ; 15 . \mathrm{MgCl}_{2} ; 16 . \mathrm{CaCl}_{2} ; 17 . \mathrm{Vc} ; 18 . \mathrm{V}_{\mathrm{b} 12} ; 19 . \mathrm{P} ; 20 . \mathrm{FeS}$

$\mathrm{O}_{4} ; 21$ blank

Melamine recoveries

\begin{tabular}{|c|c|c|c|c|}
\hline $\begin{array}{c}\text { The actual } \\
\text { content }\end{array}$ & $\begin{array}{c}\text { Calculate the } \\
\text { content }(\mathrm{ppm})\end{array}$ & $\begin{array}{c}\text { Recovery } \\
\text { rate }(\%)\end{array}$ & $\begin{array}{c}\text { Calculate the } \\
\text { content }(\mathrm{ppm})\end{array}$ & $\begin{array}{c}\text { Recovery } \\
\text { rate }(\%)\end{array}$ \\
\hline 0.2 & 0.193 & 97.4 & 0.205 & 102 \\
\hline 0.3 & 0.301 & 100.2 & 0.304 & 101 \\
\hline 0.5 & 0.514 & 103 & 0.502 & 100.2 \\
\hline
\end{tabular}

\section{Conclusions}

The detection of melamine in feed protein has been established: The method can successfully detected $0.7 \mathrm{ppm}$ melamine in feed. This concentration of melamine can be directly found by the naked eye because of no nano-gold, formed. The qualitative detection limit of the concentration of melamine in feed is $0.7 \mathrm{ppm}$. No color change in the solution can be observed with the naked eye because of no formation of nano-gold. Nano-gold solution was wine red.

According to the absorption values of gold nanoparticles at different concentrations of melamine it can be found that a linear relationship between absorption values of gold nanoparticles and the concentration of melamine in the range of $0.1 \sim 0.5 \mathrm{ppm}$ melamine. So the concentration of melamine in feed between $0.1 \sim 0.5 \mathrm{ppm}$ can be detected quantitatively by UV-visible spectrophotometer

\section{Reference}

[1] Chung Yong this feed and research in animal foods melamine detection technology. [D], Hebei Agricultural University, 2012J. Clerk Maxwell, A Treatise on Electricity and Magnetism, 3rd ed., vol. 2. Oxford: Clarendon, 1892, pp.68-73

[2] Söhngen, N.L.Uber bakterien, welche methan ab kohlenstoffnahrung and energiequelle gebrauchen[J]. Parasitenkd. Infectionskr. Abt, 1906, 15:513-517.

[3] Murrell J C, McDonald I R, Gilbert B. Regulation of expression of methane monooxygenases by copper ions. Trends in Microbiology, 2000, 8(5): $221-225$ 
[4] Liang Zhanbei, Shi Yi, Yue Jin. Advances in the research of Methanotroph[J]. Chinese Journal ofEcology, 2004,5: 198-205

[5] Mark W F,Daniel W, Patricia P. Trichloroethylene degradation by methylosinus trichosporiumOB3bmutantants ina sequencing biofim reactor[J]. Science\&Technology, 1996,104 (29): 2655-2644

[6] Hanson RS, Hanson TE. Methanotrophic bacteria[J]. Microbiological reviews, 1996,60(2):439471.

[7] Knapp CW, Fowle DA, Kulczycki E, Roberts JA, Graham DW. Methane monooxygenase gene expression mediated by methanobactin in the presence of mineral copper sources[J]. Proceedings of the National Academy of Sciences, 2007,104(29):12040-12045.

[8] Semrau JD, DiSpirito AA, Yoon S. Methanotrophs and copper[J]. FEMS microbiology reviews, 2010,34(4):496-531.

[9] Mafune F, Kohno J, Takeda Y, et al. Formation of gold nanoparticles by laser ablation in aqueous solution ofsurfactant[J]. J. Phys. Chem. B, 2001, 105(22): 5114-5120.

[10] Daniel M C, Astruc D. Gold Nanoparticles : assembly, supramolecular chemistry, quantum-size-related properties, and applications toward biology, catalysis, and nanotechnology [J]. Chemical Reviews, 2004, 104(1) : 293-346 